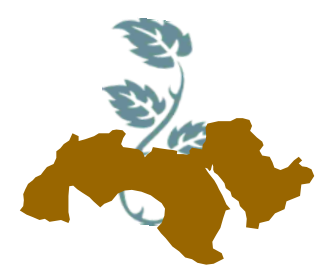

\title{
BIOLOGICAL ACTIVITY AND DISINFECTION OF ANOSAN SOLUTION WITH INHERENT APPLICABILITY 1- INACTIVATION OF PATHOGENIC MICROORGANISMS
}

1- Ecabiotec, Meddle East Dubai, UAE.

Issa Lootah ${ }^{1}$, Abdelhamid ${ }^{3}$ A.G., Galal ${ }^{1}$ S.R., Lamis Bin Harib", Hoehn $^{2}$ M.G., Langner ${ }^{2}$ A. and El Dougdoug ${ }^{4}$ K.A.

2- Ecabiotec, Morfelden-Walldorf, Germany

3- Botany Dept. Fac. of Sci., Benha Univ., Benha, Egypt

4- Agric., Microbiology Dept., Fac. of Agric., Ain Shams Univ., P.O. Box 68, Hadayek Shobra 11241, Cairo, Egypt.

Corresponding author: Email: drdougdoug@yahoo.com

Keywords: ANOSAN, Bactericidal, Fungicidal, Pathogenic bacteria

\begin{abstract}
The pathogenic and spoilage microorganisms affect human health directly or indirectly and become increasingly important in most countries. Novel antimicrobial agents and disinfectants have become necessary due to the rise of antibiotic resistance phenomena. The current study investigate the inhibitory infect of ANOSAN on pathogenic bacteria and toxigenic fungi. Chemical analysis was performed for ANOSAN. The antimicrobial activity of ANOSAN was carried out using agar well diffusion assay and mean growth inhibition percentage and Minimum Inhibitory Concentration (MIC). The antibiofilm activity was conducted using Biofilm formation assay and the impact of the disinfectant on the preformed biofilm was visualized by Scanning Electron Microscope (SEM). The chemical composition of ANOSAN comprised very low amount of Sodium (0.034\%), Chloride $(0.01 \%)$, Hypochlorite $(0.014 \%)$ and Organic matter $(0.0062 \%)$. ANOSAN low concentration showed a broad spectrum of antibacterial activities against Gram positive, Gram negative bacteria and fungi. The MIC $(0.781 \mathrm{mg} / \mathrm{ml})$ was observed for Vibrio cholerae, Pseudomonas aeruginosa and Staphylococcus aureus. Sub-inhibitory concentrations of ANOSAN have successfully inhibited biofilm formation of the above mentioned bacterial patho-
\end{abstract}

gens. The ANOSAN appeared to be effective as bactericidal against PS. aeruginosa and Staph. aureus. The time kill assay was observed between (0-6h) and between (0-3h) of exposure for both pathogens, respectively, and the viable bacterial counts remained undetectable after the previous time in a confirmatory experiment. Scanning Electron Microscopy (SEM) was conducted to confirm the antimicrobial activity of ANOSAN against Staph. aureus and Ps. aeruginosa. These data directly illustrate the destructive effects of the ANOSAN on the pathogenic bacteria. This work clarified that ANOSAN water had bactericidal and fungicidal activity along with inhibiting the ability of pathogenic bacteria to form biofilms, thus providing a good alternative to the use of traditional antimicrobials in food industry, pharmaceutical and medical applications.

\section{INTRODUCTION}

Nosocomial and hospital acquired infections are becoming a global threat and increases at regular fashion. Until the last decade, it was thought that contamination of environmental surfaces played a negligible role in transmission of infections and efforts only depended on effective hand hygiene of healthcare professionals and workers (Ali, et al 2015). However, the transmission of clinically important pathogens such as Acinetobacter spp., Norovirus, Staphylococcus aureus, Clostridium difficile and vancomycin-resistant entero- 
cocci was documented to occur through environmental surfaces (Desai, et al 2016). Disinfectants such as chlorine and hypochlorus acid were commonly used for eradications of such acquired infections but still an effective and friendly disinfectants are in demand.

The most common chlorine disinfectant is household bleach, it is cheap and readily available. It is used in concentrations ranging from 1\% (1 part bleach mixed with 99 parts tap water) to $10 \%$ (1 part bleach mixed with 9 parts tap water) depending on the type of organic matter present on the surface to be disinfected. Chlorine disinfectants are UV and heat sensitive and can corrode metals, deteriorate fabrics, and irritate mucous membranes, eyes and skin. Oxidizing Agents are most commonly available as stabilized peroxides, some of which come blended with iodophors or quaternary ammonia. Some of these products are effective against a broad range of pathogens including enveloped and non-enveloped viruses, vegetative bacteria, fungi, and bacterial spores. They can be used to disinfect equipment surfaces and are safe for the environment. Pathogenic bacteria have been shown to attach to a wide variety of foodcontact and non-contact surfaces (Lee Wong, 1998). Such attachment of microorganisms to food contact surfaces frequently referred to as biofilms, can impact the food industry by complicating sanitation and increasing the risk of cross contamination with spoilage and pathogenic microorganisms (Austin et al 1998 and (Lin et al 2011). In this study, investigation the effect of ANOSAN on selected pathogenic bacteria and toxigenic fungi was elucidated.

\section{MATERIALS AND METHODS}

References test strains: Bacillus subtilis, Escherichia coli ATCC10536, Pseudomonas aeruginosa ATCC 9027, Staphylococcus aureus ATCC6538, Salmonella typhi ATCC 14028, Vibrio cholera, Aspergillus niger ATCC 16404, Rhizopus stoloniforme ATCC 14036 and Candida albicans ATCC 10231 were obtained from stock cultures of Cairo MIRCEN at Fac. of Agric. Ain-Shams Univ., Egypt.

Source of ANOSAN: composed of water (99\%) activated electrochemically, sodium chloride $<1 \%$, sodium hypochlorite $<0.1 \%$, made in Dobi, UAE by Ecabiotec, Meddle East manufacturing LLC 98901 Dubai under license of Ecabiotec AG Morfelden wall dorf Germany.
Chemical analysis of ANOSAN: ANOSAN was analyzed chemically at the Center Labs. Fac. of Agric., Ain Shams Univ., Egypt.

Media for microbiological analysis: The media consist of the following ingredients $(\mathrm{g} / \mathrm{L})$ : Mueller-Hinton agar (Mueller and Hinton, 1941) constituted of Beef extract(2.0), Acid Hydrolysate of Casein (17.5), Starch (1.5), Agar (17.0) and Distilled water $(1.0 \mathrm{~L})$, Final $\mathrm{pH}\left(\right.$ at $\left.25^{\circ} \mathrm{C}\right) 7.3 \pm 0.1$. Nutrient agar constituted of Beef extract (3.0), Peptone (5.0), Sodium chloride, $\mathrm{NaCl}$ (5.0), Agar 15.0 and Distilled water $(1.0 \mathrm{~L})$. Final $\mathrm{pH}\left(\right.$ at $\left.25^{\circ} \mathrm{C}\right)$ $7.0 \pm 0.2$. Sabouraud Dextrose Agar (CarlierGwendoline, 1948) constituted of peptone (10.0), Dextrose (20.0), Agar (20.0) and Distilled water $(1.0 \mathrm{~L})$. Final $\mathrm{pH}\left(\right.$ at $\left.25^{\circ} \mathrm{C}\right) 7.4 \pm 0.2$. Trypticase soy agar (Difco, UK).

\section{Antimicrobial activity}

Disc diffusion assay: Impregnated well with sterilized cork borer with Anosan in concentration (100ul/well) in inoculated agar plates with tested bacteria for 24h. Sabouraud dextrose Agar (SDA), (Difco) was inoculated with tested fungi before the agar solidification. Negative controls were done using sterile distilled water. Then, plates were incubated at $37^{\circ} \mathrm{C}$ for $24 \mathrm{~h}$ for bacteria and $28^{\circ} \mathrm{C}$ for 4 days of fungi. The susceptibility of the bacteria was estimated by measuring the diameter of the zones of inhibition and recorded values as the average of three replicates (NARMS, 2002).

Broth micro dilution method: was used to determine mean growth inhibition percentage of tested bacteria and fungi by ELISA reader according to NCCLS/CLSI, (2007). The bacterial suspension equivalent to the turbidity of $0.5 \mathrm{McF}$ arland standard $\left(10^{8} \mathrm{cfu} / \mathrm{ml}\right)$ prepared from a fresh subculture of tested bacteria in MHB then the suspension was diluted to $\left(10^{6} \mathrm{cfu} / \mathrm{ml}\right)$ using $\mathrm{MHB}$. The fungal suspension equivalent to the turbidity of 0.5 McFarland standard prepared from a fresh subculture of tested fungi in Sabouraud Dextrose Broth (Difco). The suspension was diluted to $\left(10^{6} \mathrm{cfu} / \mathrm{ml}\right)$ using SDB. The adjusted microbial inoculants $(100 \mu \mathrm{L})$ were added to each well of sterile 96-well flat-bottomed microtiter plate containing the tested of Anosan 100 ( $\mu \mathrm{L} /$ well). As a result, last inoculum concentration of $\left(5 \times 10^{5} \mathrm{CFU} / \mathrm{ml}\right)$ was obtained in each well. Three wells containing microbial suspension without ANOSAN used as (Growth control) and two wells containing only media as (background control) were included in this plate. Optical 
densities were measured at $(620 \mathrm{~nm})$ after $24 \mathrm{~h}$ at $37^{\circ} \mathrm{C}$ using ELISA microplate reader (Sun RiseTECAN, Inc. ${ }^{\circledR}$, USA). The percentage of bacterial growth reduction (GR \%) was estimated using as reference the control treatment as:

$$
G R \%=\frac{C-T}{C x 100}
$$

Where: $C$ is the cell concentrations under the control treatment and $T$ is the cell concentrations under the extract treatment. Three replicates were considered. The results were recorded as means \pm $\mathrm{SE}$ of the triplicate experiment (NCCLS/CLSI, 2007).

Determination of Minimum Inhibitory Concentration (MIC): The MICs were determined by the broth micro dilution method as approved by the guidelines of Clinical and Laboratory Standards Institute (NCCLS/CLSI, 2007). The micro titre plates were prepared by adding $(100 \mu \mathrm{L})$ of MHB for bacteria, $(100 \mu \mathrm{L})$ of SDB for fungi followed by an addition of ANOSAN at a volume of $(100 \mu \mathrm{L})$. Twenty micro liters $(20 \mu \mathrm{L})$ of bacterial suspension (0.5 McFarland standards), twenty micro liters $(20 \mu \mathrm{L})$ of fungal suspension were added to each of the wells except the control wells (control wells contained broth only and distilled water only). An automatic ELISA micro plate reader (Sun RiseTECAN, Inc. ${ }^{\circledR}$, USA) adjusted at $620 \mathrm{~nm}$ was used to measure the absorbance of the plates before and after incubation at $37^{\circ} \mathrm{C}$ after $24 \mathrm{~h}$ for bacteria and after $48 \mathrm{~h}$ at $28^{\circ} \mathrm{C}$ for fungi. The lowest concentration of ANOSAN resulting in inhibition of bacterial or fungal growth was recorded as the MIC (NCCLS/CLSI, 2007).

\section{Antivirulence activity}

Biofilm formation assay: The bacterial cultures were tested for their ability to form biofilm using tissue culture plate assay as described by Christensen et al (1995). Briefly, bacteria isolates were inoculated in10 $(\mathrm{ml})$ of trypticase soy broth with $2 \%$ glucose. The inoculated broths were incubated at $37^{\circ} \mathrm{C}$ for $24 \mathrm{~h}$. The cultures were then diluted 1:100 with fresh medium. Individual wells of sterile 96- well flat bottom polystyrene tissue culture treated plates (Sigma-Aldrich, Costar, USA) were filled with $(200 \mu \mathrm{L})$ of the diluted cultures with
0.5 McFarland standard. Negative control wells inoculated with $200 \mu \mathrm{L}$ sterile broth medium. The plates were incubated at $37^{\circ} \mathrm{C}$ for $24 \mathrm{~h}$. After incubation, contents of each well were removed (free floating bacteria) by gentle tapping. The wells were washed with $0.2(\mathrm{ml})$ of phosphate buffer saline $(\mathrm{pH}=7.2)$ four times. Biofilm formed by bacteria adherent to the wells were fixed by $2 \%$ sodium acetate and stained by crystal violet $(0.1 \%)$. Excess stain was removed by using deionized water and plates were kept for drying. Optical density (O.D.) of stained adherent biofilm was obtained by using micro ELISA microtiter- plate reader (Sun Rise-TECAN, Inc. $\AA$, USA) at wavelength (570 $\mathrm{nm})$. The experiment was performed intriplicate and repeated three times. The interpretation of biofilm production was done according to the criteria of (Stepanovic et al 2007).

Biofilm inhibition assay: The ANOSAN was tested for their potential to prevent bacterial biofilm formation of strong producing isolates at sub MIC concentration against tested bacterial isolates. An aliquot of two-fold serial dilutions was prepared in the 96-well microtiter plate containing trypticase soy broth with $2 \%$ glucose to obtain the previous concentrations $(100 \mu \mathrm{L})$. Bacterial suspensions $\left(50 \mu \mathrm{L} ; 5 \times 10^{5} \mathrm{cfu} / \mathrm{ml}\right.$, final concentration) were then transferred into the plate. Distilled water was employed as a (negative control). Inoculated medium without the ANOSAN was used as the (positive control). Following incubation at $37^{\circ} \mathrm{Cfor} 24 \mathrm{~h}$ the effect of the test agent on the bacterial growth was evaluated using the microplate reader at optical density of (570nm) according to Lin et al (2011).

Scanning Electron Microscope (SEM): Treated bacterial cultures with ANOSAN at (MICs) concentrations at $0.25 \mathrm{ml} / 1.0 \mathrm{ml}$ water for $P S$. aeruginosa and Staph. aureus were incubated for 24 hat $30^{\circ} \mathrm{C}$ and non-treated one were investigated by SEM (Ultee et al 2002) as follow : The samples were fixated by glutheraldhyde $2.5 \%$ and dehydrated by serial dilution of ethanol using automatic tissue processor (Leica EM TP). Then the samples drying using $\mathrm{CO}_{2}$ critical point drier (Tousimis Audosamdri-815). The samples coated by gold sputter coater (SPI-Module). The samples were exanimated by scanning electron microscopy (JEOLJSM-5500LV) by using high vacuum mode at the Regional Center of Mycology and Biotechnology, Cairo, Egypt. 


\section{RESULTS}

ANOSAN chemistry: The Chemical composition of disinfectant ANOSAN included very low amount of Sodium $(0.034 \%)$, Chloride $(0.01 \%)$, Hypochlorite $(0.014 \%)$ and Organic matter
$(0.0062 \%)$. The results clarified the disinfectant ANOSAN free chemical substances and organic materials.

Disinfection characteristics: ANOSAN was assessed for antimicrobial activity to inhibit pathogenic microorganisms.

Table 1. Minimum inhibition concentration and time-kill assay of Bacteria (CFU/ml) using ANOSAN

\begin{tabular}{|l|c|c|c|c|c|c|c|c|}
\hline \multirow{3}{*}{ Anosan Con. } & \multicolumn{6}{|c|}{ No. of colonies (CFU/mI) at different Exposure period } \\
\cline { 2 - 9 } & \multicolumn{2}{|c|}{$\mathbf{0 ( m i n )}$} & \multicolumn{2}{|c|}{$\mathbf{5 ( m i n )}$} & \multicolumn{2}{c|}{$\mathbf{1 5}$ (min) } & \multicolumn{2}{c|}{$\mathbf{3 0 ( m i n )}$} \\
\cline { 2 - 9 } & $\mathbf{S T}^{*}$ & BS $^{\text {** }}$ & ST & BS & ST & BS & ST & BS \\
\hline Undiluted & $0.5 \times 10^{5}$ & $0.2 \times 10^{5}$ & $4 \times 10^{4}$ & $0.2 \times 10^{5}$ & $1.3 \times 10^{4}$ & $0.2 \times 10^{5}$ & $0.5 \times 10^{4}$ & $0.1 \times 10^{5}$ \\
$2 \%$ & $59 \times 10^{5}$ & $8 \times 10^{5}$ & - & - & - & & $2 \times 10^{4}$ & $8 \times 10^{5}$ \\
$5 \%$ & $42 \times 10^{5}$ & $7 \times 10^{5}$ & $4 \times 10^{4}$ & $2 \times 10^{5}$ & $2 \times 10^{5}$ & $1 \times 10^{5}$ & $2 \times 10^{4}$ & $0.9 \times 10^{5}$ \\
$10 \%$ & $40 \times 10^{5}$ & $5 \times 10^{5}$ & $6 \times 10^{4}$ & $1.5 \times 10^{5}$ & $3 \times 10^{4}$ & $0.9 \times 10^{5}$ & $2 \times 10^{4}$ & $0.7 \times 10^{5}$ \\
$15 \%$ & $25 \times 10^{5}$ & $1.5 \times 10^{5}$ & $6 \times 10^{4}$ & $0.8 \times 10^{5}$ & $2 \times 10^{4}$ & $0.2 \times 10^{5}$ & $2 \times 10^{4}$ & $0.3 \times 10^{5}$ \\
\hline
\end{tabular}

*Denotes for Staph. aureus ${ }^{* *}$ denotes for Bacillus Subtilis

Antibacterial activity: The disinfectant ANOSAN showed a promising effect against both of $S$. typhi enterica and $B$. subtilis (Table 2). It must be used for a longer time than 15 min.as an exposure / contact time. Finally it was noticed that $B$. subtilis was not completely influenced using the disinfectant Anosan at the investigated durations and concentration.

The diameter of clear zone inhibition and mean growth inhibition of $E$. coli; Ps. aeruginosa; $K$. pneumonia; M. tuberculosis; S. typhi; Staph. aureus and $V$. cholerae were exhibited susceptibility towards used ANOSAN with diameter zones of inhibition 6.7, 5.33, 13, 7.25, 8.33, 12.16; 12.25 $(\mathrm{mm})$ as well as the mean growth inhibition were 62.5, 72; 91.2; 80.24; 78.16; 81.6, 75.82 OD respectively (Table, 2). MICs value of ANOSAN against the tested bacteria growth at concentrations $10 \mathrm{ml}^{-1}$; while against $V$. cholerae was $3 \mathrm{ml}^{-1}$.

Among seven tested bacterial isolates, the strong biofilm producing isolates were Ps. aeruginosa, K. pneumonia, M. tuberculosis, S. Typhi, Staph. aureus and $V$. cholera with optical density $0.52,0.59,0.69 ; 0.66 ; 0.74$ and 0.85 OD respectively. While, moderate biofilm producing was 0.23 (O.D.) for E. coli.

Biofilm inhibition was investigated for potential to prevent biofilm formation against strong biofilm producing bacterial isolates ( $P$ s. aeruginosa, Staph. aureus and $V$. cholerae) grown with different sub (MICs) concentrations. The results in Table (2) showed that biofilm inhibition percentages were 75.4, 88.7, 83.37, 75.76, 77.13, 82.2 and $85.2 \%$ at the following sub (MICs) concentrations
$10 \mathrm{~mL}^{-1}$ of B. cereus, E. coli, K. Pneumonia M. tuberculosis, S. typhi and Staph. aureus and $3 \mathrm{~mL}^{-1}$ of $V$. cholerae, respectively.

\section{Antifungal activity}

The disinfectant ANOSAN was tested against toxigenic fungi in terms of exposure time and dilution factor. It was showed a promising effect against $A$. flavus (Table 3). The disinfectant ANOSAN was better to be used in concentrated without dilution. Also it must be concentrated and used for a longer time (30 min). Finally it was noticed that $A$. flavus was not completely influenced using the disinfectant ANOSAN at the recorded durations.

In addition, ANOSAN displayed strong antifungal activity as shown in Table (4). In the presence of ANOSAN, the inhibition zones diameter against A. niger, A. flavus, $R$ h. stolonifeme and $C$. albicans were 18.2; 15.4, 16.2; and $12.1(\mathrm{~mm})$ respectively. On the other hand, the mean growth inhibition percentage against the same tested fungi and yeasts were 92.2, 79.4, 82.7 and $62.5 \%$ respectively. MICs value of ANOSAN against the toxigenic $A$. niger, $A$. flavus, $R h$. stolonifera and yeast growth at concentrations $10 \mathrm{ml}^{-1}$ were 12.0, 10, 5.0 and $10.0 \mathrm{ml}^{-1}$ respectively.

\section{Effect of ANOSAN on bacterial cells via SEM}

SEM images observations confirmed the effect of ANOSAN on bacteria morphological structure via the physical damage and considerable morphological alterations. Treated pathogenic bacteria with relevant MICs of ANOSAN were incubated for $24 \mathrm{~h}$ at $30^{\circ} \mathrm{C}$. 
Table 2. The diameter of clear zones inhibition, mean growth inhibition percentages and Minimum Inhibitory Concentrations of ANOSAN against pathogenic bacteria

\begin{tabular}{|c|c|c|c|c|c|c|c|}
\hline Assessments & $\begin{array}{l}E . \\
\text { coli }\end{array}$ & $\begin{array}{c}\text { Ps. } \\
\text { aeruginosa }\end{array}$ & $\begin{array}{c}\text { K. } \\
\text { Pneumonia }\end{array}$ & $\begin{array}{c}\text { M. } \\
\text { tuberculosis }\end{array}$ & $\begin{array}{c}\text { S. } \\
\text { Typhi }\end{array}$ & $\begin{array}{l}\text { Staph. } \\
\text { aureus }\end{array}$ & $\begin{array}{c}\text { V. } \\
\text { Cholera }\end{array}$ \\
\hline (Gl) (mm) & 6.7 & 5.33 & 13 & 7.25 & 8.33 & 12.16 & 12.25 \\
\hline MICs & 62.5 & 72 & 91.2 & 80.24 & 78.16 & 81.6 & 75.82 \\
\hline $\operatorname{MICs}\left(\mathrm{mLL}^{-1}\right)$ & 10 & 10 & 10 & 10 & 10 & 10 & 3 \\
\hline Biofilm (O.D) & 0.32 & 0.52 & 0.59 & 0.69 & 0.66 & 0.74 & 0.85 \\
\hline Biofilm reduction \% & 75.4 & 88.7 & 83.37 & 75.76 & 77.13 & 82.2 & 85.2 \\
\hline
\end{tabular}

Each value is mean of 3 replicates

$\mathrm{Gl}=$ growth inhibition (inhibition zones diameter $\mathrm{mm}$ )

ANOSAN (2ml/well)

$\mathrm{MGI}=$ Mean growth inhibition (broth micro-dilution method) by ELISA plate reader

MICs =Minimum Inhibitory Concentrations

Biofilm formation assay of bacterial isolates using (Tissue culture plate method by ELISA reader), biofilm formation was

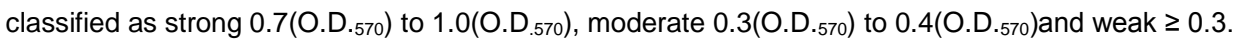

Table 3. Minimum inhibitory concentration and time killed of ANOSAN inhibited A. flavus

\begin{tabular}{|l|c|c|c|c|}
\hline \multirow{2}{*}{ Anosan concentration } & \multicolumn{4}{|c|}{ No. of colonies (CFU/ml) at different Exposure time } \\
\cline { 2 - 5 } & $\mathbf{0}(\mathbf{m i n})$ & $\mathbf{5}(\mathbf{m i n})$ & $\mathbf{1 5}(\mathbf{m i n})$ & $\mathbf{3 0}(\mathbf{m i n})$ \\
\hline Concentrated & $37 \times 10^{5}$ & $1 \times 10^{5}$ & $0.5 \times 10^{5}$ & Zero \\
$2 \%$ & - & - & - & $46 \times 10^{5}$ \\
$5 \%$ & $42 \times 10^{5}$ & $52 \times 10^{5}$ & $35 \times 10^{5}$ & $36 \times 10^{5}$ \\
$10 \%$ & $45 \times 10^{5}$ & $46 \times 10^{5}$ & $37 \times 10^{5}$ & $34 \times 10^{5}$ \\
$15 \%$ & $48 \times 10^{5}$ & $32 \times 10^{5}$ & $31 \times 10^{5}$ & $30 \times 10^{5}$ \\
\hline
\end{tabular}

Table 4. The diameter of clear zones inhibition, mean growth inhibition percentages and Minimum Inhibitory Concentrations of ANOSAN against toxigenic fungi and yeast

\begin{tabular}{|c|c|c|c|}
\hline Tested fungi & $\begin{array}{c}\text { Clear zones } \\
\text { diameter }(\mathbf{m m})\end{array}$ & $\begin{array}{c}\text { Mean growth inhibition } \\
(\%)\end{array}$ & $\begin{array}{c}\text { Minimum Inhibitory } \\
\text { Concentrations MICs }\left(\mathbf{m L}^{-1}\right)\end{array}$ \\
\hline A. niger & 18.2 & 92.2 & 12.0 \\
A. flavus & 15.4 & 79.4 & 10.0 \\
Rh. stolonifer & 16.2 & 82.7 & 5.0 \\
C. albicans & 12.1 & 62.5 & 10.0 \\
\hline
\end{tabular}


From all the SEM observations, the images illustrated in (Fig. 1) directly seemed that normal cells (control) were intact and showed a smooth surface. ANOSAN caused severe damage to the treated bacteria. Gram negative and Gram positive cells treated with ANOSAN appeared to be shrunk with distorted cell wall, as well as the remains were flaccid. The Gram positive bacterium was more affected negatively than the Gram negative one as shown in Fig. 1.

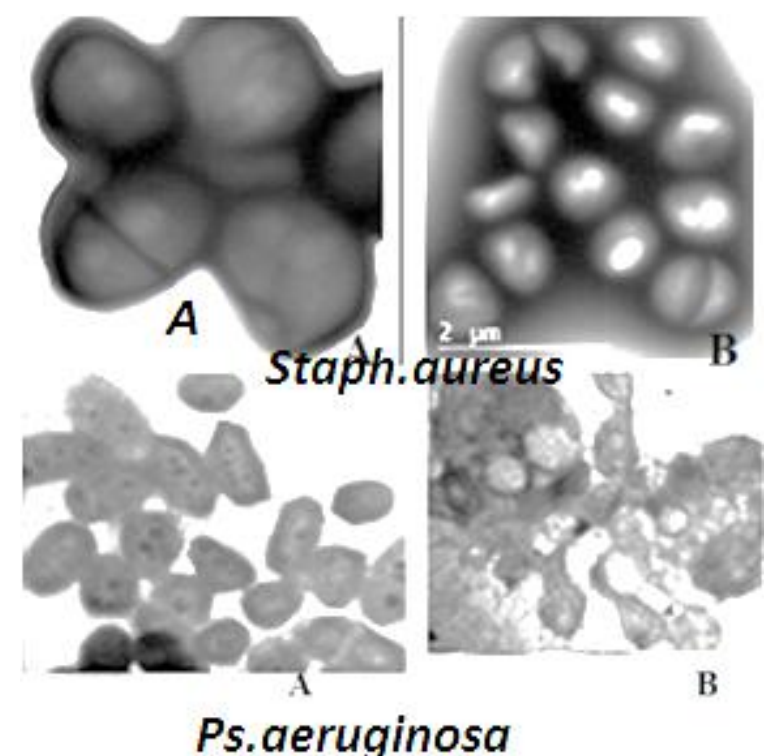

Fig. 1. Micrograph showing morphological alterations in pathogenic bacteria. Staph. aureus and Ps. aeruginosa where A) Indicates untreated (control) bacteria as compare to the same bacteria exposed to ANOSAN (B).

\section{DISCUSSION}

ANOSAN showed broad spectrum antimicrobial activities against Gram positive and Gram negative tested bacteria and toxigenic fungi. The antimicrobial activity of ANOSAN could be in part due to the presence of hypochlorite. Sodium hypochlorite fulfills many requirements as the ideal disinfectant and furthermore it has an excellent cleaning action. The effectiveness of sodium hypochlorite in the cleaning and disinfection processes depends on the concentration of available chlorine and the $\mathrm{pH}$ of the solution. Hypochlorous acid $(\mathrm{HOCl})$ is a weak acid and dissociates to the hypochlorite ion $(-\mathrm{OCl})$ and proton $(\mathrm{H}+)$ depending on the solution $\mathrm{pH}$. It is generally believed that $\mathrm{HOCl}$ is the active species in the germicidal action, whereas the concentration of $-\mathrm{OCl}$ is a key factor determining the cleaning efficiency (Fukuzaki, 2006). ANOSAN was developed by preparing $0.85 \% \mathrm{NaCl}$ solution and measuring the concentration of free chlorine and hypochlorous acid after giving the solution a short electrical impulse of 20 seconds. (Kim et al 2008). Weak acid hypochlorous solution (WAHS) is a chlorine-based disinfectant that is produced by mixing $\mathrm{NaClO}$ and $\mathrm{HCl}$ in water and adjusting it to a weak acidity of around $\mathrm{pH} 6$ using purpose-built equipment. WAHS has been reported to have an excellent microbicidal effect against a broad range of microorganisms related to human health, so WAHS has practical applicability in hospitals or the food industry (Ono et al 2012).

Active chemical contents of ANOSAN have been shown to cause disruption of the cellular membrane, inhibition of ATPase activity, and release of intracellular ATP and other constituents of several microorganisms such as E. coli, E. coli 0157:H7, L. monocytogenes, Ps. aeruginosa, S. enteritidis, and Staph .aureus (Moreno et al 2006 and Raybaudi-Massilia et al 2009). In the same study, increased membrane permeability is a major factor in the mechanism of antimicrobial action, 
whereas compounds may disrupt membranes and cause a loss of cellular integrity and eventual cell death. Minimum inhibitory concentrations are important in diagnostic laboratories to confirm resistance of micro-organisms to an antimicrobial agent, to give a definitive answer when a borderline result is obtained by other methods of testing, and also to monitor the activity of new antimicrobial agents (Barros et al 2007).

Microorganisms form biofilm to protect themselves against adverse conditions. These biofilms can be comprised of single or mixed species (Kumar et al 2008), although mixed species biofilms offer added protection because they are more stable and create a larger and thicker biofilm mass (Donlan, 2002). Once the microorganisms multiply and colonize, they attach to the surface and form a biofilm (Zottola, 2001 and Donlan, 2002). Attachment of microorganisms to food contact surfaces can impact the food industry economically, and through associated health, pathogenic and spoilage bacteria have been shown to attach to a wide variety of food contact and non-contact surfaces (Zottola, 2001). So, finding natural novel biofilm inhibitor for food safety processing and products is very vital.

Biofilm inhibition studies carried out using ANOSAN sub (MIC) have successfully inhibited biofilm formation of tested pathogenic bacteria. The results clearly, indicate that, the enhanced antibiofilm effect of ANOSAN sub (MIC) in microtitre plate assay. These results are in harmony with (Motoko et al 2014) who had been reported the antibiofilm effect of WAHS against biofilm of human pathogenic bacteria. The increased antibiofilm effect due to the inhibition of exopolysaccharide synthesis limiting the formation of biofilm (Giaouris et al 1999) or due to diffusion of ANOSAN through the channels present in the biofilm may explain ANOSAN antibiofilm function.

SEM images directly illustrate the destructive effects of ANOSAN on the tested bacteria. There are many possible explanations for the observations in harmony with these results. The literature suggests that the active components of hypochlorous acid $(\mathrm{HOCl})$ and hypochlorite ion $(\mathrm{OCl}-)$ might bind to the cell surface and then penetrate to the target sites, possibly the phospholipid bilayer of the cytoplasmic membrane and membrane-bound enzymes (Shan et al 2007). The SEM images show that some cells present damage as pores or deformity in the cell walls. Also, some authors have suggested that the damage to the cell wall and cytoplasmic membrane was the loss of structural integrity and the ability of the membrane to act as a permeability barrier (Packiyasothy and Kyle 2002 and Filipowicz et al 2003). Most of the cells were observed to get clustered and stick to each other. The distortion of the cell physical structure would cause the expansion and destabilization of the membrane and would increase membrane fluidity, which in turn, would increase passive permeability (Ultee et al 2002).

This work clarified that ANOSAN water had bactericidal and fungicidal activity along with inhibiting the ability of pathogenic bacteria to form biofilms, thus providing a good alternative to the use of traditional antimicrobials in food industry, pharmaceutical and medical applications.

\section{REFERENCES}

Ali, M., Nelson, A.R., Lopez, A.L. and Sack, D. 2015. Updated global burden of cholera in endemic countries. PLoS Negl Trop Dis 9(6), e0003832.

Austin, J.W., Sanders, G., Kay, W.W. and Collinson, S.K. 1998. Thin aggregative fimbriae enhance Salmonella enteritidisbiofilm formation. FEMS Microbiol. FEMS Microbiol. Lett., 162, 295-301.

Barros, L., Calhelha, R., Vaz, J., Ferreira, I., Baptista, P. and Estevinho, L. 2007. Antimicrobial activity and bioactive compounds of Portuguese wild edible mushrooms methanolic extracts. Eur. Food Res. Technol., 225, 151156.

Carlier-Gwendoline, I.M. 1948. Weekly Epidemiological Brit. J. Derm. Syph., 60, 61-63.

Christison, C.A., Lindsay, C.A. and Von Holy A. 2008. Microbiological survey of ready-to-eat foods and associated preparation surfaces in retail delicatessens, Johannesbyrg, South Africa. Food Control, 19, 727-733.

Desai, S.N., Pezzoli, L., Martin, S., Costa, A., Rodriguez, C., Legros, D. and Perea W. 2016. A second affordable oral cholera vaccine: implications for the global vaccine stockpile. Lancet Glob Health., 4, 223-224.

Donlan, R.M. 2002. Biofilms: Microbial life on surfaces. Emerg. Infect. Dis., 8, 881-890.

Filipowicz, N., Kaminski, M., Kurlenda, J., Asztemborska, M. and Ochocka, J. 2003. Anti-bacterial and antifungal activity of juniper berry oil and its selected components. Phytother. Res., 17, 227-231. 
Fukuzaki S. 2006. Mechanisms of actions of sodium hypochlorite in cleaning and disinfection processes. Biocontrol. Sci. 11, 147-157.

Giaouris, E., Heir, E., Hébraud, M., Chorianopoulos, N., Langsrud, S., Møretrø, T., Habimana, O., Desvaux, M., Renier, S. and Nychas, G.J. 2014. Attachment and biofilm formation by foodborne bacteria in meat processing environments: Causes, implications, role of bacterial interactions and control by alternative novel methods. Meat Sci., 97, 298309.

Kim, H.J., Lee, J.G., Kang, J.W., Cho, H.J., Kim, H.S., Byeon, H.K. and Yoon .J.H., 2008 . Effects of a low concentration hypochlorous Acid nasal irrigation, 118, 1862-1867.

Kumar, K., Shukla, R., Singh, P., Prasad, C.S. and Dubey, N.K. 2008. Assessment of Thymus vulgaris $\mathrm{L}$. essential oil as a safe botanical preservative against post-harvest fungal infestation of food commodities. Innovat. Food Sci. \& Emerg. Tech., 9, 575-580.

Lee Wong, A.C. 1998. Biofilms in food processing environments. J. Dairy Sci., 81, 2765-2770.

Lin, M.H., Chang, F.R., Hua, M.Y., Wu, Y.C. and Liu, S.T. 2011. Inhibitory effects of 1, 2, 3, 4, 6penta-O-galloyl- $\beta$-D-glucopyranose on biofilm formation by Staphylococcus aureus. Antimicrob. Agents Chemo-ther., 55, 1021-1027.

Moreno, S., Scheyer, T., Romano, C. and Vojnov, A. 2006. Antioxidant and antimicrobial activities of rosemary extracts linked to their polyphenol composition. Free Radic. Res., 40, 223-231.

Motoko, T., Takimoto, K. Aya Zamoto-Niikura, and Yamada, Y.K. 2014. Effect of Weak Acid Hypochlorous Solution on Selected Viruses and Bacteria of Laboratory Rodents, Exp. Anim., 63, 141-147.

Mueller, J.H. and Hinton, J. 1941. A protein-free medium for primary isolation of Gonococcus and Meningococcus. Exp. Biol. Med. (Maywood), 48, 330-333.
NARMS, 2002. National Antimicrobial Resistance Monitoring System, Enteric Bacteria. CDC, USA.

NCCLS/CLSI" National Committee for Clinical Laboratory Standards / Clinical and Laboratory Standards Institute, 2007. Performance standards for antimicrobial susceptibility testing; Seventeenth informational supplement, M2-A9 and M7-A7. Wayne, P.A., U.S.A.

Ono, T., Yamashita, K., Murayama, T., Sato, T. 2012. Microbicidal effect of weak acid hypochlorous solution on various microorganisms. Biocontrol. Sci. 17, 129-133.

Packiyasothy, E. and Kyle, S. 2002. Antimicrobial properties of some herb essential oils. Food Aust., 54, 384-387.

Raybaudi-Massilia, R., Mosqueda-Melgar, J., Soliva-Fortuny, R. and Martin-Belloso, 0. 2009. Control of Pathogenic and Spoilage Microorganisms in Fresh-cut Fruits and Fruit 192 Juices by Traditional and Alternative Natural Antimicrobials. Compr. Rev. Food. Sci. Food Saf., 8, 157-180.

Shan, B., Cai, Y.Z., Brooks, J.D. and Corke, H. 2007. Antibacterial properties and major bioactive compon-ents of cinnamon stick (Cinnamomumburm -annii): Activity against foodborne pathogenic bacteria. J. Agric. Food Chem., 55, 5484-5490.

Stepanović, S., Vuković, D., Hola, V., Di Bonaventura, G., Djukić, S., Cirković, I. and Ruzicka, F. 2007. Quantification of biofilmin microtiter plates: overview of testing conditions and practical recommendations for assessment of biofilm production by Staphy-lococci. APMIS, 115, 891-899.

Ultee, A., Bennik, M. and Moezelaar, R. 2002. The phenolic hydroxyl group of carvacrol is essential for action against the food-borne pathogen Bacillus cereus. Appl. Environ. Microbiol., 68, 1561-1568.

Zottola, E.A. 2001. Reflections on Salmonella and other "wee beasties" in foods. Food Technol., $55,60-67$. 